(C) 2018. This manuscript version is made available under the CC-BY-NC-ND 4.0

license http://creativecommons.org/licenses/by-nc-nd/4.0/

\title{
Impact of gastrostomy placement on nutritional status, physical health and parental well-being of females with Rett syndrome: A longitudinal study of an Australian population
}

\section{Authors}

Kingsley Wong, Jenny Downs, Carolyn Ellaway, Gordon Baikie, Madhur Ravikumara, Peter Jacoby, John Christodoulou, Elizabeth J Elliott, Helen Leonard

Kingsley Wong MBBS MPH, Telethon Kids Institute, The University of Western Australia, Perth, WA, Australia

Jenny Downs BApplSci (physio) MSc PhD, Telethon Kids Institute, The University of Western Australia, Perth, WA, Australia; School of Physiotherapy and Exercise Science, Curtin University, Perth, WA, Australia.

Carolyn Ellaway MBBS PhD, Disciplines of Genetic Medicine and Paediatrics and Child Health, The University of Sydney, Western Sydney Genetics Program, The Children's Hospital at Westmead, Sydney, NSW, Australia.

Gordon Baikie MD PhD, Department of Developmental Medicine, Royal Children's Hospital, Melbourne, VIC, Australia.

Madhur Ravikumara MBBS MRCPCH FRACP, Department of Gastroenterology, Princess Margaret Hospital for Children, Perth, WA, Australia.

Peter Jacoby MSc, Telethon Kids Institute, The University of Western Australia, Perth, WA, Australia.

John Christodoulou MBBS PhD FRACP FFSc FRCPA, Disciplines of Genetic Medicine and Paediatrics and Child Health, The University of Sydney, Western Sydney Genetics Program, The Children's Hospital at Westmead, Sydney, NSW, Australia.

Elizabeth J Elliott MBBS MD MPhil FRACP FRCPCH FRCP, Discipline of Paediatrics and Child Health, The University of Sydney, The Children's Hospital at Westmead, Sydney, NSW, Australia; The Sydney Children's Hospitals Network (Westmead), Sydney, NSW, Australia.

Helen Leonard MBChB MPH, Telethon Kids Institute, The University of Western Australia, Perth, WA, Australia.

Corresponding Author:

Helen Leonard

Telethon Kids Institute

100 Roberts Road, Subiaco

Western Australia, 6008, Australia

Phone +61419956946

Fax +61 894897700

Helen.Leonard@telethonkids.org.au

The study was supported by an National Health and Medical Research Council (NHMRC) project grant \#1004384 and an NHMRC program grant \#572742. Helen Leonard is supported by an NHMRC senior research fellowship \#1117105. There is no conflict of interest to disclose. 


\begin{abstract}

\section{Objectives}

To evaluate how age-related trends in nutritional status, physical health and parental wellbeing in Rett syndrome may be related to gastrostomy placement, and to examine the impact of the procedure on mortality.
\end{abstract}

\title{
Study design
}

We included 323 females from the Australian Rett Syndrome Database and analyzed their demographic, genetic and child and parental health data collected from over six waves of follow-up questionnaire between 2000 and 2011. We used mixed-effects models to estimate the association between repeated measures of outcomes and age, gastrostomy placement and their interaction, and Cox proportional hazards regression models to estimate relative risks of mortality for individuals with gastrostomy.

\section{Results}

Nearly a third (30.3\%) of the cases underwent gastrostomy placement. Nutritional status based on weight, height, and body mass index (BMI) improved over time, and BMI was greater in individuals with gastrostomy placement than in those without (adjusted beta 0.9, 95\% CI 0.0-1.7). There was no association between gastrostomy placement and individual's physical health outcomes or parental physical and mental health, nor did the age trend of these outcomes vary by gastrostomy insertion status. Nevertheless, among those at risk of sub-optimal weight, all-cause mortality rate was higher in those who had gastrostomy placement group compared with those who had not (hazard ratio 4.1, 95\% CI 2.0-8.5).

\section{Conclusion}

Gastrostomy placement was associated with improvement in BMI in females with Rett syndrome, but its long-term impact on individuals and their families is unclear. 


\section{Introduction}

Rett syndrome (RTT) is a rare but severe neurodevelopmental disorder mainly seen in females. ${ }^{1}$ The estimated incidence is 1 in 8,500 female births. ${ }^{2}$ It is associated with severe disability and there is no specific treatment or cure. Until recently, epidemiological and outcome data have been relatively sparse.

The main diagnostic criteria of classical RTT now include: a history of partial or complete loss of acquired purposeful hand skills; a history of loss of acquired spoken language; impairment or inability to walk; and the presence of stereotypic hand movements. ${ }^{3}$ Comorbidities include scoliosis, poor growth, osteoporosis, epilepsy, breathing abnormalities and sleep difficulties. ${ }^{4}$ In 1999, a causal association was identified between RTT and mutations in the methyl $\mathrm{CpG}$ binding protein 2 (MECP2) gene, ${ }^{5}$ and now more than 500 disease-causing MECP2 mutations have been reported. ${ }^{6}$

Feeding difficulties and poor growth are commonly seen in RTT and may be associated with poor oro-motor function, limited self-feeding skills, gastro-esophageal reflux disease, breathing dysfunction and constipation. ${ }^{7-9}$ There is a progressive decline in height, weight, and body mass index with age, likely influenced by genotype. ${ }^{10,11}$ Gastrostomy feeding tube placement is a therapeutic option for addressing feeding difficulties and poor nutritional status. To date, its effectiveness in RTT has only been studied in a US clinic-based series where the outcomes assessed were limited to anthropometric data without consideration of other aspects of quality of care such as child and parental well-being. ${ }^{12}$ In keeping with the quality of care literature ${ }^{13}$ and recent recommendations relating to the assessment of gastrostomy outcomes ${ }^{14}$, the aims of this study were to 1) investigate agerelated trends in nutritional status, physical health and parental well-being in individuals with RTT, and 2) to evaluate how these changes may be related to gastrostomy placement. We also examined the impact of gastrostomy on mortality. 


\section{Methods}

\section{Study design and setting}

Established in 1993, the Australian Rett Syndrome Study began recruiting individuals with RTT from cases identified through the Australian Paediatric Surveillance Unit, the Rett Syndrome Association of Australia and other sources, ${ }^{15}$ including clinicians who manage the three specialized Rett syndrome clinics in Sydney, Melbourne, and Perth. At the core of the current study is the Australian Rett Syndrome Database, which stores demographic, genetic and health data on individuals with RTT at the time of recruitment, as well as responses from parents/caregivers to follow-up questionnaires that have been administered to primary caregivers since 1996. From 2000 onwards, questionnaires have included measures of functional ability; behavior and hand function; information on medical conditions; episodes of illness; use of health, therapy, respite and day-care services; feeding; equipment use; and education. From 2002 onwards, questionnaires have also included measures of family functioning and health and well-being of the primary caregiver (e.g., parents). Seven waves of follow-up questionnaires (1996, 2000, 2002, 2004, 2006, 2009 and 2011) have been distributed. Pertinent clinical data, including data recorded during inpatient care and outpatient attendance, were extracted from medical records to enrich the dataset captured by the questionnaire.

Ethics approval for data collection was provided by the Human Research Ethics Committee of Princess Margaret Hospital for Children, Perth (1909/EP); Royal Perth Hospital, Perth (RA-12/007); Women's and Children's Hospital, Adelaide (HREC/13/WCHN/57); Royal Children's Hospital, Melbourne (31339A); Monash Medical Centre, Melbourne (14203Q); Sydney Children's Hospitals Network, Sydney (LNR-2011-1013); Mater Children's Hospital, Brisbane (1878/LNR); and Royal Children's Hospital, Brisbane (HREC/12/QRCH/76). Ethics approval was also obtained to link the cohort to the 
National Death Index administered by the Australian Institute of Health and Welfare (EC380). All families provided informed consent before participating. The study design can be considered as a single cohort, multiple age design, a variant of the cross-sequential longitudinal design. ${ }^{16}$

\section{Study participants}

Females with a clinically or genetically confirmed diagnosis of RTT, whose parents/caregivers had completed at least one follow-up questionnaire from 2000, were included in the study. Health outcomes, including individuals' anthropometric and physical health data, were collected from questionnaires in 2000, 2002, 2004, 2006, 2009 and 2011 and hospital records, whilst data on parental well-being outcomes were gathered from questionnaires in 2002, 2006, 2009 and 2011. For health outcomes, 323 individuals with RTT were eligible for the study. The number of questionnaires completed ranged from one to six with a median of three. A total of 88 parents/caregivers completed all six waves of questionnaires, 47 had completed five, 44 four, 40 three, 53 two and 51 one. Therefore, a total number of 1,216 responses were available for 323 individuals. For parental well-being outcomes, parents/caregivers of 311 individuals completed at least one of the four waves of questionnaires. The number of questionnaires completed ranged from two to four per patient with a median of two. A total of 116 parents/caregivers had completed all four questionnaires, 70 completed three, 57 completed two and 68 completed one. The total numbers of individuals and responses were 311 and 856 respectively.

\section{Variable definitions}

Weight $(\mathrm{kg})$ and height $(\mathrm{cm})$ data were provided by parents/caregivers in the followup questionnaires, in addition to those ascertained from medical records. Body mass index (BMI) $\left(\mathrm{kg} / \mathrm{m}^{2}\right)$ was calculated as weight divided by height squared. Parental well-being was measured using the 12-Item Short-Form Health Survey (SF-12) Physical Component 
Summary (PCS) and Mental Component Summary (MCS) scales, with higher scores representing better health. ${ }^{17}$ The PCS domains are named as follows: "Physical Functioning", "Role-physical”, "Bodily Pain", and "General Health”, whilst the MCS domains are "Vitality", "Social Functioning", "Role-emotional" and "Mental Health". The instrument was included in the 2002, 2006, 2009 and 2011 follow-up questionnaires and was answered by either parent of the individual. The PCS and MCS scores have been shown to be valid in Australian and other populations. ${ }^{18,19}$ Using the population mean item weight method, data with up to three of the six key items (i.e., items that contribute predominantly to a given score) missing and any number of non-key items missing for either PCS or MCS were imputed. ${ }^{20}$ Total number of illness episodes was defined as the sum of the reported number of upper (e.g., cold, ear infection, tonsillitis) and lower (e.g., bronchitis, pneumonia) respiratory infections experienced by the individual in the 12 months prior to completion of each followup questionnaire. Cumulative length of hospital stay was defined as the sum of reported number of days in hospital being admitted for respiratory tract infections, seizures or gastrointestinal problems in the 12 months prior to completion of the follow-up questionnaire.

Gastrostomy placement was defined by whether the intervention had been reported at the time of the follow-up questionnaire completion and was coded as a binary variable: Yes/No. Other variables included in the analysis were age at completion of each questionnaire centered around overall median value of 15 years, MECP2 gene mutation type, feeding method, mobility, ever learned to walk, sleep disturbances, scoliosis and breath holding. Family variables included in the analysis were residence, type of respondent, respondent's age, respondent's work status, respondent's highest level of education, use of formal respite care, household annual income, geographic remoteness of parental home, and socio-economic status of parental household based on the Index of Relative Socio-economic 
Advantage and Disadvantage (IRSAD) ${ }^{21}$ with lower scores representing disadvantaged $(<50 \%)$ and higher scores representing advantaged areas $(>=50 \%)$. The "in care" subgroup comprises females who were no longer living in the family home.

\section{Statistical analysis}

Cross-sectional descriptive statistics, reported as mean (SD), median (range) or $\mathrm{n}(\%)$ where appropriate, were used to summarize the outcomes, exposure, and all explanatory/confounding variables. Two generalized linear mixed-effects models were used to investigate the effect of individual's age on the nutritional status, physical health and parental well-being outcomes (Model 1) and their relationship to gastrostomy placement (Model 2). Main effects of age at questionnaire completion, questionnaire year, and pertinent explanatory/confounding variables were included in both models. Model 2 also included the main effect of gastrostomy placement and an interaction term between age at questionnaire completion and gastrostomy placement, and the sample was limited to individuals with suboptimal weight which was defined as ever having a weight-for-age z-score (WAZ) of less than -1 at time of questionnaire completion during the follow-up period. Such restriction was applied so the benefits or otherwise of gastrostomy placement on the outcomes would be better understood in individuals who were likely to receive the procedure. The z-score was calculated using the 2000 Centers for Disease Control and Prevention growth reference for the United States. ${ }^{22}$ For both models, linear age effect was examined for all outcomes while quadratic age effect was investigated only for anthropometric measures. All outcomes were treated as continuous variables except illness episodes and length of stay which were treated as count variables. Choice of explanatory/confounding variables was guided by a priori knowledge of associations with outcomes as well as the exposure of interest. Unadjusted and adjusted estimates of the fixed effects and their $95 \%$ confidence intervals were reported. 
For survival analysis, individuals with a WAZ $<-1$ during the follow-up period, were included in the analysis. Individuals became at risk at birth and entered the study at time of first recorded low weight-for-age z-score (to account for left truncation as individuals might have died prior to recruitment). Follow-up time was censored at the end of the observation period, which was defined as the earliest of the following: date of death or $31^{\text {st }}$ Dec 2014 (to account for right censoring as death has not yet been observed during the follow-up period). The Kaplan-Meier method was used to estimate the survival function for the whole group and also for those who had never had gastrostomy. After splitting the follow-up time at age at first gastrostomy placement, a Cox proportional hazards model was fitted with a time-varying variable to indicate whether individuals have undergone the intervention. Hazard ratio for gastrostomy placement, adjusted for mutation type and learned to walk status, was estimated. Choice of adjustment covariates was guided by their relevance as severity indicators. The proportional hazards assumption was tested and confirmed using the Schoenfield residuals. The crude and adjusted hazard ratios and their $95 \%$ confidence intervals were presented. All analyses were carried out in Stata 14.2 (StataCorp LP, College Station, TX).

\section{Results}

Characteristics of 323 females with RTT and their families by questionnaire year are shown in Table 1 and Table 2. The median age at questionnaire completion increased from 13 years (range 1-24 years) in 2000 to 17 years (range 2-35 years) in 2011. Close to a third $(30.3 \%, \mathrm{n}=98)$ of the study population underwent gastrostomy placement. The prevalence of gastrostomy placement increased by questionnaire year from $11.9 \%$ in 2000 to $27.0 \%$ in 2011, although most of the rise occurred between 2000 and 2006. The median recruitment age dropped slightly from 7 years (range 1-18 years) to 5 years (range 1-24 years) over the decade. By calendar year, there were gains in mean weight, height, and BMI over the 10 years from 2000, and the mean MCS score improved between 2002 and 2011 (Table 3). On 
the other hand, the average PCS score and the total number of illness episodes remained relatively stable. The mean cumulative length of stay varied with no discernible trend.

\section{Longitudinal data analysis}

WEIGHT, HEIGHT AND BMI. After accounting for pertinent covariates, weight, height and BMI increased with age (weight: adjusted age $\beta 1.33,95 \%$ CI 1.16,1.50, $P$-value $<0.01$; height: adjusted age $\beta$ 1.87, 95\% CI 1.72,2.02, $P$-value $<0.01$; BMI: adjusted age $\beta$ $0.29,95 \%$ CI $0.22,0.36, P$-value $<0.01)$. BMI, specifically, was higher in those with gastrostomy placement compared to those without gastrostomy (weight: adjusted $\beta 1.46,95 \%$ CI -0.21,3.13, $P$-value 0.09; height: adjusted $\beta-0.63,95 \%$ CI -3.05,1.80, $P$-value 0.61; BMI: adjusted $\beta 0.87,95 \%$ CI 0.02,1.73, $P$-value 0.04) (Table 4). Overall, the age trend of weight, height and BMI did not differ by gastrostomy placement status (Table 4).

ILLNESS EPISODES. For the average female with RTT, the incidence of illness decreased with age (adjusted incidence rate ratio (IRR) $0.95,95 \%$ CI $0.94,0.96, P$-value $<0.01)$. There was no evidence to suggest that gastrostomy placement was associated with increased incidence of illness for a typical female (adjusted IRR 1.06, 95\% CI 0.87,1.29, $P$ value 0.57 ), and the age trend of illness episodes was not affected by gastrostomy placement (adjusted IRR 1.02, 95\% CI 0.99,1.04, $P$-value 0.18) (Table 4).

LENGTH OF HOSPITAL STAY. Average cumulative length of hospital stay of any female with RTT did not change with age (adjusted IRR 0.97, 95\% CI 0.93,1.02, $P$-value 0.27). Similarly, gastrostomy placement was not associated with longer period of stay (adjusted IRR 2.08, 95\% CI 0.86,5.04, $P$-value 0.11 ). The age trend of length of stay appeared to be similar before and after gastrostomy placement (adjusted IRR 0.94, 95\% CI $0.84,1.05, P$-value 0.24$)$ (Table 4).

Parental Physical Component Summary (PCS). No age effect on PCS score was observed after accounting for pertinent covariates (adjusted $\beta-0.14,95 \% \mathrm{CI}$ - 
$0.36,0.08, P$-value 0.21$)$. Gastrostomy placement was not related to parental physical health (adjusted $\beta-0.45,95 \%$ CI -3.08,2.19, $P$-value 0.74) (Table 4). Similarly, there was no evidence of an age trend of the score in females with gastrostomy placement compared to those without (adjusted $\beta-0.11,95 \%$ CI -0.45,0.23, $P$-value 0.53 ) (Table 4).

Parental Mental Component Summary (MCS). Similar to that of PCS, no age effect on the MCS score was observed among parents (adjusted $\beta-0.06,95 \%$ CI $0.30,0.17, P$-value 0.59 ). The score did not differ by gastrostomy placement status (adjusted $\beta-1.25,95 \%$ CI -4.25,1.75, $P$-value 0.41 ) (Table 4). In addition, having gastrostomy did not appear to affect the age-related trend of MCS score (adjusted $\beta-0.10,95 \% \mathrm{CI}-0.51,0.30, P$ value 0.63 ) (Table 4).

\section{Survival analysis}

Characteristics of the 233 females with a weight-for-age z-score of less than -1 are shown in Table 5 (online). Among them, 83 (35.6\%) individuals had had gastrostomy placement. The median age of the first gastrostomy placement was 9 years (range 1-35 years). Reported feeding difficulties, an indicator of oropharyngeal capabilities and was defined as need for special food preparation and/or observed coughing/choking when being fed liquid or soft food, were common (69.6\%) among females who never had had gastrostomy but somewhat higher $(86.4 \%)$ in those who did go on to have a gastrostomy. The estimated survival probability was $73.5 \%$ (95\% CI 46.3\%,88.4\%) at 15 years of age and $66.1 \%(95 \% \mathrm{CI} 43.5 \%, 81.3 \%)$ at 20 years of age (median survival time 33 years 8 months) based on 47 deaths over a total observation time of 2,207 person-years. When observation period related to gastrostomy placement was removed (the censor age was replaced with the age at first procedure), the estimated probability of survival in those who had not had the intervention was $91.3 \%(95 \%$ CI 76.1\%,97.0\%) and 87.3\% (95\% CI 73.4\%,94.2\%) at 15 and 20 years, respectively. After adjusting for mutation type and learned to walk status, the all- 
cause mortality rate was higher in the gastrostomy group compared with the group who never had gastrostomy placement (adjusted hazard ratio 4.07, 95\% CI 1.96,8.45, $P$-value $<0.01$ ). Among the deceased who had had gastrostomy placement $(n=30)$, the median age at first procedure was 11 years (range 3-35 years) and the median duration from first gastrostomy to death was 6 years (range 1 month-20 years).

\section{Discussion}

Gastrostomy is a frequent intervention for children with severe disabilities and feeding difficulties. In RTT it is used in nearly one-third of cases and, as we have shown, use has considerably increased since the turn of the century. The primary purpose of this study was to exploit a longitudinal, population-based database to investigate the effects of gastrostomy not only on nutritional status but also on other aspects of health, survival and parental well-being. Although BMI was higher in those with a gastrostomy, we could not demonstrate any positive age trend in parameters of nutritional status associated with gastrostomy insertion. Moreover, we did not find any beneficial effect of gastrostomy or an associated trend with age on illness episodes or length of hospital stay. Although we had hypothesized that there might be a reduction in hospitalizations associated with the use of gastrostomy, we found no evidence to support this. We also did not find any effect of gastrostomy on parental physical or mental health.

To date there have only been two studies evaluating the effect of gastrostomy on anthropometric parameters before and after gastrostomy in RTT. ${ }^{12,23}$ The first was undertaken on a convenience sample of 92 individuals with RTT followed clinically at the Texas Children's Hospital. ${ }^{12}$ Weight $(n=81)$, height $(n=73)$, and BMI $(n=81)$ z-score slopes increased post-gastrostomy compared with pre-gastrostomy with the highest increase seen in BMI and the least in height z-scores irrespective of the child's age at surgery. Similar results were seen for fat-free mass and body fat although these results were only available for a 
smaller number of individuals. The small number of cases precluded investigation by specific mutation type, and therefore mutations were grouped into categories, possibly obscuring any difference. The second study, using data from the Australian Rett Syndrome Database and published in 2014, has similarities to the US study but was limited to a comparison of weightfor-age z-scores pre- and approximately two years post-gastrostomy. ${ }^{23} \mathrm{We}$ found an increase in the z-score of, on average, 0.86 following gastrostomy.

Our previous preliminary study was the impetus for the current study which now includes data on 323 individuals obtained from multiple questionnaire waves providing over 1,200 observations relating to those with or without a gastrostomy. The extensive dataset has allowed us to investigate some of the risk and protective factors for nutritional status (Model 1) in addition to addressing our primary research question, namely the impact of gastrostomy on nutritional status, physical health, parental well-being (Model 2) and mortality in those classified as having sub-optimal weight. As might also be expected nutritional status was shown to be most compromised in those unable to walk even after adjusting for genotype.

Consistent with previous studies ${ }^{12,23}$ we showed that, in individuals with sub-optimal weight, BMI was higher in those with gastrostomy insertion compared with the group who never had had gastrostomy. We could not confirm the positive effect on weight and height seen in the US study. ${ }^{12}$ Moreover, we did not identify a different or improved trajectory in these parameters following gastrostomy. It is possible therefore that the immediate impact of gastrostomy is an increase in overall nutritional status but afterward the trajectory continues as previously. Rett syndrome-specific growth trajectories have been developed but contain no indication of the proportion of children with a gastrostomy who were included in the sample or their impact on the growth curves. ${ }^{11}$

Mortality rate was higher among individuals with RTT who received gastrostomy placement. There have been relatively few studies examining mortality in RTT because of the 
absence of population-based and longitudinal data. Aside from studies using the Australian Database,${ }^{24-27}$ in one of which a protective effect of surgical fusion on mortality in severe scoliosis was demonstrated, ${ }^{27}$ the only other comparable investigation is the US Natural History Study in which 1,090 females with RTT were followed for up to nine years, during which time 41 died. ${ }^{28}$ In this study, low WAZ increased the risk of mortality.

Ours has been the only study to investigate the impact of gastrostomy on the health and hospitalization pattern of individuals with RTT. We did not find that health outcomes were improved or hospitalization rate reduced after gastrostomy. These findings are consistent with a study which, through a retrospective review of 114 patients at Boston Children's Hospital with an abnormal swallow on video fluoroscopy, found that thickened oral feeds were more effective in reducing the rate of hospitalization in children with aspiration than was gastrostomy. ${ }^{29}$ The authors recommended a trial of thickening of feeds before gastrostomy-tube placement in this population. Our results could also reflect more careful subsequent attention being given to the management of comorbid health conditions which might have been neglected before gastrostomy insertion. Alternatively, children selected for gastrostomy rather than the continuation of oral feeding might be those who had more comorbidities. Overall, illness episodes and hospitalizations, however, were relatively infrequent in our study population.

We did not find any association between gastrostomy and the mental health of caregivers of gastrostomy recipients in the low weight group. These results were somewhat at odds with our earlier study in which families told us that after gastrostomy insertion they felt less anxious about the care of their child. ${ }^{23}$ In that study, most families noted a reduction in feeding difficulties, and coughing and choking and fatigue during feeding. They also agreed that their daughters were happier and had improved health and well-being and that medications were simpler to administer and the time taken to feed was shorter. It is possible 
that the general nature of the parental well-being measures used in our current study was unable to capture the practical benefits of gastrostomy placement we had previously documented.

There are many strengths to this study, a major one being the data source. The Australian Rett Syndrome Database, established in 1993, contains the only ongoing population-based data on this rare disorder and includes up to seven waves of longitudinal data collected since $1996 .{ }^{30}$ An additional strength is the comprehensive set of covariates, including genotype, which were available for inclusion in the analysis. Regarding limitations, there were missing data as a result of non-response or study attrition as contact was lost with some families. Other shortcomings relate to the completeness and self-reported nature of the anthropometric data, particularly the height variable which can be difficult to measure in this population, and the lack of standardized measures of nutritional status. Although we have taken into consideration pertinent confounders in our analyses, we acknowledge that females with RTT selected for gastrostomy placement, especially among those with a history of suboptimal weight, were more likely to be affected by co-morbidities (e.g., refractory epilepsy) which could have contributed to the observed results such as poorer survival outcome. Such confounding by indication is difficult to control in observational studies ${ }^{31}$ and cannot be entirely ruled out.

As enteral feeding is being increasingly used in children and adults with RTT and other disorders, improving study designs and establishing uniform methods of measuring outcomes to allow for better synthesis of evidence are urgent priorities. ${ }^{14}$ While randomized controlled trials can be used to assess other types of nutritional interventions, ${ }^{32}$ for ethical reasons these are not an option for evaluating gastrostomy feeding either in RTT or in conditions such as cystic fibrosis, ${ }^{33}$ where enteral nutrition may have a role in improving 
survival following later lung transplantation. We acknowledge that our outcome measures are incomplete, and we lack data on health costs.

Although we have now demonstrated a beneficial impact of gastrostomy on nutritional status and previously on family satisfaction, ${ }^{23}$ we have not demonstrated a longterm benefit for parental well-being, a reduction in hospitalizations following gastrostomy or a reduction in mortality. However, as changes in clinical practice occur as time progresses, it is possible that earlier gastrostomy insertion may be shown to have a more positive effect on growth, morbidity or mortality patterns. This supposition will be the subject of future research with more recently collected longitudinal data.

\section{Acknowledgement}

We thank the families participating in the Australian Rett Syndrome Study and acknowledge their continued support of Rett Syndrome research in Australia. We would also like to express our sincere gratitude to the Australian families who have contributed to the study by completing questionnaires, pediatricians and health professionals who have been involved in Rett syndrome surveillance, the Australian Paediatric Surveillance Unit, and the Rett Syndrome Association of Australia who facilitated case ascertainment in Australia. 


\section{Abbreviations}

RTT Rett syndrome

MECP2 methyl $\mathrm{CpG}$ binding protein 2

BMI body mass index

SF-12 12-Item Short-Form Health Survey

PCS Physical Component Summary

MCS Mental Component Summary

IRSAD Index of Relative Socio-economic Advantage and Disadvantage

IRR incidence rate ratio 


\section{References}

1. Hagberg B, Aicardi J, Dias K, Ramos O. A progressive syndrome of autism, dementia, ataxia, and loss of purposeful hand use in girls: Rett's syndrome: report of 35 cases. Ann Neurol. $1983 ; 14: 471-9$.

2. Fehr S, Bebbington A, Nassar N, Downs J, Ronen GM, N DEK, et al. Trends in the diagnosis of Rett syndrome in Australia. Pediatr Res. 2011;70:313-9.

3. Neul JL, Kaufmann WE, Glaze DG, Christodoulou J, Clarke AJ, Bahi-Buisson N, et al. Rett syndrome: revised diagnostic criteria and nomenclature. Ann Neurol. 2010;68:944-50.

4. Leonard H, Cobb S, Downs J. Clinical and biological progress over 50 years in Rett syndrome. Nat Rev Neurol. 2017;13:37-51.

5. Amir RE, Van den Veyver IB, Wan M, Tran CQ, Francke U, Zoghbi HY. Rett syndrome is caused by mutations in X-linked MECP2, encoding methyl-CpG-binding protein 2. Nat Genet. 1999;23:185-8.

6. Krishnaraj R, Ho G, Christodoulou J. RettBASE: Rett syndrome database update. Hum Mutat. 2017;38:922-31.

7. Schwartzman F, Vitolo MR, Schwartzman JS, Morais MB. Eating practices, nutritional status and constipation in patients with Rett syndrome. Arq Gastroenterol. 2008;45:284-9.

8. Motil KJ, Schultz RJ, Browning K, Trautwein L, Glaze DG. Oropharyngeal dysfunction and gastroesophageal dysmotility are present in girls and women with Rett syndrome. J Pediatr Gastroenterol Nutr. 1999;29:31-7.

9. Reilly S, Cass H. Growth and nutrition in Rett syndrome. Disabil Rehabil. 2001;23:11828.

10. Oddy WH, Webb KG, Baikie G, Thompson SM, Reilly S, Fyfe SD, et al. Feeding experiences and growth status in a Rett syndrome population. J Pediatr Gastroenterol Nutr. 2007;45:582-90. 
11. Tarquinio DC, Motil KJ, Hou W, Lee HS, Glaze DG, Skinner SA, et al. Growth failure and outcome in Rett syndrome: specific growth references. Neurology. 2012;79:1653-61.

12. Motil KJ, Morrissey M, Caeg E, Barrish JO, Glaze DG. Gastrostomy placement improves height and weight gain in girls with Rett syndrome. J Pediatr Gastroenterol Nutr. 2009;49:237-42.

13. Long AF, Dixon P, Hall R, Carr-Hill RA, Sheldon TA. The outcomes agenda: contribution of the UK clearing house on health outcomes. Qual Health Care. 1993;2:49-52.

14. Kapadia MZ, Joachim KC, Balasingham C, Cohen E, Mahant S, Nelson K, et al. A Core Outcome Set for Children With Feeding Tubes and Neurologic Impairment: A Systematic Review. Pediatrics. 2016;138.

15. Leonard H, Bower C, English D. The prevalence and incidence of Rett syndrome in Australia. Eur Child Adolesc Psychiatry. 1997;6 Suppl 1:8-10.

16. Nicholson J, Sanson A, Rempel L, Smart D, Patton G. Longitudinal studies of children and youth Implications for future studies. Melbourne: Australian Instiute of Family Studies; 2004.

17. Ware J, Jr., Kosinski M, Keller SD. A 12-Item Short-Form Health Survey: construction of scales and preliminary tests of reliability and validity. Med Care. 1996;34:220-33.

18. Avery J, Dal Grande E, Taylor A. Quality Of Life in South Australia as Measured by the SF12 Health Status Questionnaire : Population Norms For 2003 : Trends From 1997 - 2003. South Australia: Population Research and Outcome Studies Unit, Department of Human Services; 2004.

19. Jenkinson C, Chandola T, Coulter A, Bruster S. An assessment of the construct validity of the SF-12 summary scores across ethnic groups. J Public Health Med. 2001;23:187-94.

20. Perneger TV, Burnand B. A simple imputation algorithm reduced missing data in SF12 health surveys. J Clin Epidemiol. 2005;58:142-9. 
21. ABS. 2033.0.55.001 - Census of Population and Housing: Socio-Economic Indexes for Areas (SEIFA), Australia, 2011 Caberra: Australian Bureau of Statistics; 2013 [Available from: http://www.abs.gov.au/ausstats/abs@.nsf/Lookup/2033.0.55.001main+features100042011.

22. Ogden CL, Kuczmarski RJ, Flegal KM, Mei Z, Guo S, Wei R, et al. Centers for Disease Control and Prevention 2000 growth charts for the United States: improvements to the 1977 National Center for Health Statistics version. Pediatrics. 2002;109:45-60.

23. Downs J, Wong K, Ravikumara M, Ellaway C, Elliott EJ, Christodoulou J, et al. Experience of gastrostomy using a quality care framework: the example of rett syndrome. Medicine (Baltimore). 2014;93:e328.

24. Anderson A, Wong K, Jacoby P, Downs J, Leonard H. Twenty years of surveillance in Rett syndrome: what does this tell us? Orphanet J Rare Dis. 2014;9:87.

25. Freilinger M, Bebbington A, Lanator I, De Klerk N, Dunkler D, Seidl R, et al. Survival with Rett syndrome: comparing Rett's original sample with data from the Australian Rett Syndrome Database. Dev Med Child Neurol. 2010;52:962-5.

26. Laurvick CL, de Klerk N, Bower C, Christodoulou J, Ravine D, Ellaway C, et al. Rett syndrome in Australia: a review of the epidemiology. J Pediatr. 2006;148:347-52.

27. Downs J, Torode I, Wong K, Ellaway C, Elliott EJ, Izatt MT, et al. Surgical fusion of early onset severe scoliosis increases survival in Rett syndrome: a cohort study. Dev Med Child Neurol. 2016;58:632-8.

28. Tarquinio DC, Hou W, Neul JL, Kaufmann WE, Glaze DG, Motil KJ, et al. The Changing Face of Survival in Rett Syndrome and MECP2-Related Disorders. Pediatr Neurol. 2015;53:402-11.

29. McSweeney ME, Kerr J, Amirault J, Mitchell PD, Larson K, Rosen R. Oral Feeding Reduces Hospitalizations Compared with Gastrostomy Feeding in Infants and Children Who Aspirate. J Pediatr. 2016;170:79-84. 
30. Downs J, Leonard H. Quantitative and qualitative insights into the experiences of children with Rett syndrome and their families. Wien Med Wochenschr. 2016;166:338-45.

31. Bosco JL, Silliman RA, Thwin SS, Geiger AM, Buist DS, Prout MN, et al. A most stubborn bias: no adjustment method fully resolves confounding by indication in observational studies. J Clin Epidemiol. 2010;63:64-74.

32. Turck D, Braegger CP, Colombo C, Declercq D, Morton A, Pancheva R, et al. ESPENESPGHAN-ECFS guidelines on nutrition care for infants, children, and adults with cystic fibrosis. Clin Nutr. 2016;35:557-77.

33. Hollander FM, van Pierre DD, de Roos NM, van de Graaf EA, Iestra JA. Effects of nutritional status and dietetic interventions on survival in Cystic Fibrosis patients before and after lung transplantation. J Cyst Fibros. 2014;13:212-8. 
Table 1. Characteristics of 323 females with Rett syndrome, by questionnaire year

\begin{tabular}{|c|c|c|c|c|c|c|}
\hline & \multicolumn{6}{|c|}{ Questionnaire year } \\
\hline & 2000 & 2002 & 2004 & 2006 & 2009 & 2011 \\
\hline \multicolumn{7}{|l|}{$\begin{array}{l}\text { Had had gastrostomy } \\
\text { placement, } n(\%)\end{array}$} \\
\hline No & $140(88.1)$ & $153(81.8)$ & $157(78.1)$ & $154(73.7)$ & $165(74.0)$ & $173(73.0)$ \\
\hline Yes & $19(11.9)$ & $34(18.2)$ & 44 (21.9) & $55(26.3)$ & $58(26.0)$ & $64(27.0)$ \\
\hline $\begin{array}{l}\text { Age at first gastrostomy } \\
\text { placement (years), median (range) }\end{array}$ & $9(3-18)$ & $10(3-23)$ & $9(1-27)$ & $9(1-30)$ & $9(1-30)$ & $9(1-35)$ \\
\hline $\begin{array}{l}\text { Age at questionnaire completion } \\
\text { (years), median (range) }\end{array}$ & $13(1-24)$ & $13(2-27)$ & $15(2-29)$ & $15(2-30)$ & $18(2-34)$ & $17(2-35)$ \\
\hline \multicolumn{7}{|l|}{ Mutation type, n (\%) } \\
\hline Large deletion & $6(3.8)$ & $9(4.8)$ & $11(5.5)$ & $12(5.7)$ & $13(5.8)$ & $15(6.3)$ \\
\hline Early truncation & $10(6.3)$ & $13(7.0)$ & $11(5.5)$ & $11(5.3)$ & $12(5.4)$ & $13(5.5)$ \\
\hline C-terminal deletion & $14(8.8)$ & $15(8.0)$ & $18(9.0)$ & $20(9.6)$ & $23(10.3)$ & $25(10.5)$ \\
\hline p.Arg106Trp & $4(2.5)$ & $3(1.6)$ & $5(2.5)$ & $8(3.8)$ & $8(3.6)$ & $10(4.2)$ \\
\hline p.Arg133Cys & $8(5.0)$ & $10(5.3)$ & $11(5.5)$ & $11(5.3)$ & $18(8.1)$ & $19(8.0)$ \\
\hline p.Thr158Met & $14(8.8)$ & $16(8.6)$ & $16(8.0)$ & $17(8.1)$ & $18(8.1)$ & $21(8.9)$ \\
\hline p.Arg168* & $15(9.4)$ & $16(8.6)$ & $19(9.5)$ & $16(7.7)$ & $15(6.7)$ & $22(9.3)$ \\
\hline p.Arg $255^{*}$ & $7(4.4)$ & $7(3.7)$ & $10(5.0)$ & $11(5.3)$ & $15(6.7)$ & $13(5.5)$ \\
\hline p.Arg270* & $12(7.5)$ & $14(7.5)$ & $14(7.0)$ & $13(6.2)$ & $15(6.7)$ & $14(5.9)$ \\
\hline p.Arg294* & $10(6.3)$ & $12(6.4)$ & $16(8.0)$ & $16(7.7)$ & $15(6.7)$ & $14(5.9)$ \\
\hline p.Arg306Cys & $8(5.0)$ & $9(4.8)$ & $10(5.0)$ & $11(5.3)$ & $9(4.0)$ & $10(4.2)$ \\
\hline Other & $13(8.2)$ & $15(8.0)$ & $16(8.0)$ & $18(8.6)$ & $17(7.6)$ & $18(7.6)$ \\
\hline Negative & $38(23.9)$ & $48(25.7)$ & 44 (21.9) & $45(21.5)$ & $45(20.2)$ & $43(18.1)$ \\
\hline \multicolumn{7}{|l|}{ Feeding method, $\mathrm{n}(\%)$} \\
\hline Oral & $137(86.2)$ & $155(82.9)$ & $158(78.6)$ & $162(77.5)$ & $170(76.2)$ & $178(75.1)$ \\
\hline Enteral & 19 (11.9) & $31(16.6)$ & 42 (20.9) & $44(21.1)$ & $47(21.1)$ & $53(22.4)$ \\
\hline Missing & $3(1.9)$ & $1(0.5)$ & $1(0.5)$ & $3(1.4)$ & $6(2.7)$ & $6(2.5)$ \\
\hline \multicolumn{7}{|l|}{ Mobility, n (\%) } \\
\hline Walks normally & $26(16.4)$ & $54(28.9)$ & $47(23.4)$ & $49(23.4)$ & 60 (26.9) & $69(29.1)$ \\
\hline Walking impaired & $34(21.4)$ & $52(27.8)$ & $53(26.4)$ & $48(23.0)$ & $57(25.6)$ & $63(26.6)$ \\
\hline Cannot walk with support & $97(61.0)$ & $81(43.3)$ & $98(48.8)$ & $108(51.7)$ & $105(47.1)$ & $96(40.5)$ \\
\hline Missing & $2(1.3)$ & $0(0)$ & $3(1.5)$ & $4(1.9)$ & $1(0.4)$ & $9(3.8)$ \\
\hline \multicolumn{7}{|l|}{ Sleeping disturbances, $\mathrm{n}(\%)$} \\
\hline None & $14(8.8)$ & $20(10.7)$ & $21(10.4)$ & $47(22.5)$ & $58(26)$ & $88(37.1)$ \\
\hline Sometimes & $16(10.1)$ & $19(10.2)$ & $19(9.5)$ & 39 (18.7) & 40 (17.9) & $43(18.1)$ \\
\hline Often & $121(76.1)$ & $146(78.1)$ & $156(77.6)$ & $110(52.6)$ & $118(52.9)$ & $91(38.4)$ \\
\hline Missing & $8(5)$ & $2(1.1)$ & $5(2.5)$ & $13(6.2)$ & $7(3.1)$ & $15(6.3)$ \\
\hline \multicolumn{7}{|l|}{ Scoliosis, n (\%) } \\
\hline None & $71(44.7)$ & $75(40.1)$ & $71(35.3)$ & $72(34.4)$ & $78(35)$ & $74(31.2)$ \\
\hline Mild & $67(42.1)$ & $90(48.1)$ & $106(52.7)$ & $102(48.8)$ & $105(47.1)$ & $114(48.1)$ \\
\hline Severe & $7(4.4)$ & $7(3.7)$ & $6(3.0)$ & $13(6.2)$ & $11(4.9)$ & $11(4.6)$ \\
\hline Surgically treated & $12(7.5)$ & $15(8.0)$ & $17(8.5)$ & $20(9.6)$ & $28(12.6)$ & $31(13.1)$ \\
\hline Missing & $2(1.3)$ & $0(0)$ & $1(0.5)$ & $2(1.0)$ & $1(0.4)$ & $7(3.0)$ \\
\hline \multicolumn{7}{|l|}{ Breath holding, $\mathrm{n}(\%)$} \\
\hline None & $44(27.7)$ & $38(20.3)$ & $52(25.9)$ & $61(29.2)$ & 75 (33.6) & $73(30.8)$ \\
\hline Sometimes & $53(33.3)$ & 84 (44.9) & $66(32.8)$ & $69(33.0)$ & 80 (35.9) & $88(37.1)$ \\
\hline Often & $59(37.1)$ & $65(34.8)$ & $82(40.8)$ & $77(36.8)$ & $66(29.6)$ & $67(28.3)$ \\
\hline Missing & $3(1.9)$ & $0(0)$ & $1(0.5)$ & $2(1)$ & $2(0.9)$ & $9(3.8)$ \\
\hline
\end{tabular}

Note: Percentages of categories within variable may not add up to 100 due to rounding

$\mathrm{n}$, number of questionnaire completed; $n$, number of individuals 
Table 2. Characteristics of the families of 323 females with Rett syndrome, by questionnaire year

\begin{tabular}{|c|c|c|c|c|c|c|}
\hline & \multicolumn{6}{|c|}{ Questionnaire year } \\
\hline & 2000 & 2002 & 2004 & 2006 & 2009 & 2011 \\
\hline \multicolumn{7}{|l|}{ Place of residence, $\mathbf{n}(\%)$} \\
\hline Parental home & $0(0)$ & $174(93)$ & $167(83.1)$ & $171(81.8)$ & $181(81.2)$ & $188(79.3)$ \\
\hline Group home/In care ${ }^{\wedge}$ & $0(0)$ & $10(5.3)$ & $33(16.4)$ & $36(17.2)$ & $42(18.8)$ & $44(18.6)$ \\
\hline Missing & $159(100)$ & $3(1.6)$ & $1(0.5)$ & $2(1.0)$ & $0(0)$ & $5(2.1)$ \\
\hline \multicolumn{7}{|l|}{ Respondent, n (\%) } \\
\hline Natural mother & $0(0)$ & $174(93)$ & $165(82.1)$ & $154(73.7)$ & $161(72.2)$ & $173(73)$ \\
\hline Natural father & $0(0)$ & $0(0)$ & $2(1.0)$ & $16(7.7)$ & $16(7.2)$ & $15(6.3)$ \\
\hline Other including carer & $0(0)$ & $10(5.3)$ & $33(16.4)$ & $37(17.7)$ & $46(20.6)$ & $44(18.6)$ \\
\hline Missing & $159(100)$ & $3(1.6)$ & $1(0.5)$ & $2(1.0)$ & $0(0)$ & $5(2.1)$ \\
\hline Respondent's age* (years), median (range) & - & $\begin{array}{c}40(21-62) \\
n=172\end{array}$ & $\begin{array}{c}41(23-62) \\
n=166\end{array}$ & $\begin{array}{c}43(28-66) \\
n=168\end{array}$ & $\begin{array}{c}45(28-69) \\
n=177\end{array}$ & $\begin{array}{c}45(25-72) \\
n=187\end{array}$ \\
\hline \multicolumn{7}{|l|}{ Respondent's work status, n (\%) } \\
\hline Full time at home & $0(0)$ & $63(33.7)$ & $78(38.8)$ & $82(39.2)$ & $73(32.7)$ & $86(36.3)$ \\
\hline Full-time of part-time work & $0(0)$ & $64(34.2)$ & $84(41.8)$ & $80(38.3)$ & $94(42.2)$ & $93(39.2)$ \\
\hline In care ${ }^{\wedge}$ & $0(0)$ & $10(5.3)$ & $33(16.4)$ & $41(19.6)$ & $43(19.3)$ & $44(18.6)$ \\
\hline Missing & $159(100)$ & $50(26.7)$ & $6(3.0)$ & $6(2.9)$ & $13(5.8)$ & $14(5.9)$ \\
\hline \multicolumn{7}{|l|}{ Respondent's highest level of education, $\mathrm{n}(\%)$} \\
\hline Non-tertiary & $0(0)$ & $67(35.8)$ & $84(41.8)$ & $86(41.1)$ & $80(35.9)$ & $80(33.8)$ \\
\hline Tertiary & $0(0)$ & $69(36.9)$ & $77(38.3)$ & $79(37.8)$ & $87(39.0)$ & 97 (40.9) \\
\hline In care ${ }^{\wedge}$ & $0(0)$ & $10(5.3)$ & $33(16.4)$ & $36(17.2)$ & $43(19.3)$ & $44(18.6)$ \\
\hline Missing & $159(100)$ & $41(21.9)$ & $7(3.5)$ & $8(3.8)$ & $13(5.8)$ & $16(6.8)$ \\
\hline \multicolumn{7}{|l|}{$\begin{array}{l}\text { Respondent's use of } \\
\text { formal respite care, } n(\%)\end{array}$} \\
\hline None & $0(0)$ & 99 (52.9) & $125(62.2)$ & $34(16.3)$ & $37(16.6)$ & $42(17.7)$ \\
\hline Any & $0(0)$ & $75(40.1)$ & 36 (17.9) & $126(60.3)$ & $130(58.3)$ & $136(57.4)$ \\
\hline In care ${ }^{\wedge}$ & $0(0)$ & $10(5.3)$ & $33(16.4)$ & $36(17.2)$ & $43(19.3)$ & 44 (18.6) \\
\hline Missing & $159(100)$ & $3(1.6)$ & $7(3.5)$ & $13(6.2)$ & $13(5.8)$ & $15(6.3)$ \\
\hline \multicolumn{7}{|l|}{ Household income, $n(\%)$} \\
\hline$<\$ 50,000$ & $0(0)$ & $89(47.6)$ & $82(40.8)$ & $76(36.4)$ & $67(30.0)$ & $57(24.1)$ \\
\hline$>=\$ 50,000$ & $0(0)$ & $53(28.3)$ & $52(25.9)$ & $59(28.2)$ & $77(34.5)$ & $80(33.8)$ \\
\hline Prefer not to answer & $0(0)$ & $32(17.1)$ & $33(16.4)$ & $36(17.2)$ & $32(14.3)$ & $47(19.8)$ \\
\hline In care ${ }^{\wedge}$ & $0(0)$ & $10(5.3)$ & $33(16.4)$ & $36(17.2)$ & $43(19.3)$ & $44(18.6)$ \\
\hline Missing & $159(100)$ & $3(1.6)$ & $1(0.5)$ & $2(1.0)$ & $4(1.8)$ & $9(3.8)$ \\
\hline \multicolumn{7}{|l|}{ Remoteness of parental home, $n(\%)$} \\
\hline Major Cities & $92(57.9)$ & $106(56.7)$ & $111(55.2)$ & $114(54.5)$ & $125(56.1)$ & $130(54.9)$ \\
\hline Regional or remote & $66(41.5)$ & $71(38.0)$ & $57(28.4)$ & $59(28.2)$ & $56(25.1)$ & $63(26.6)$ \\
\hline In care ${ }^{\wedge}$ & $0(0)$ & $10(5.3)$ & $33(16.4)$ & $36(17.2)$ & $42(18.8)$ & $44(18.6)$ \\
\hline Missing & $1(0.6)$ & $0(0)$ & $0(0)$ & $0(0)$ & $0(0)$ & $0(0)$ \\
\hline \multicolumn{7}{|l|}{ Socio-economic status (IRSAD centile), n (\%) } \\
\hline$<50 \%$ & $58(36.5)$ & $65(34.8)$ & $47(23.4)$ & $45(21.5)$ & $59(26.5)$ & $63(26.6)$ \\
\hline$>=50 \%$ & $100(62.9)$ & $112(59.9)$ & 120 (59.7) & $127(60.8)$ & $122(54.7)$ & $130(54.9)$ \\
\hline In care ${ }^{\wedge}$ & $0(0)$ & $10(5.3)$ & 33 (16.4) & $36(17.2)$ & $42(18.8)$ & 44 (18.6) \\
\hline Missing & $1(0.6)$ & $0(0)$ & $1(0.5)$ & $1(0.5)$ & $0(0)$ & $0(0)$ \\
\hline
\end{tabular}


Table 3. Descriptive statistics of nutritional status, physical health and parental well-being outcomes of females with Rett syndrome, by questionnaire year

\begin{tabular}{|c|c|c|c|c|c|c|c|}
\hline & 2000 & 2002 & Questio & naire year & 2009 & 2011 & $\begin{array}{l}\text { Number of } \\
\text { individuals or } \\
\text { families }\end{array}$ \\
\hline $\begin{array}{l}\text { Number of } \\
\text { questionnaire } \\
\text { completed }\end{array}$ & 159 & 187 & 201 & 209 & 223 & 237 & 323 \\
\hline $\begin{array}{l}\text { Weight }(\mathrm{kg}) \text {, } \\
\text { mean (SD) }\end{array}$ & $\begin{array}{c}31.1(15.4) \\
n=146\end{array}$ & $\begin{array}{c}32.2(14.8) \\
n=174\end{array}$ & $\begin{array}{c}33.7(15.3) \\
n=179\end{array}$ & $\begin{array}{c}35.1(14.3) \\
n=201\end{array}$ & $\begin{array}{c}39.1(16.6) \\
n=200\end{array}$ & $\begin{array}{c}37.9(17.0) \\
n=216\end{array}$ & 319 \\
\hline $\begin{array}{l}\text { Height }(\mathrm{cm}) \text {, } \\
\text { mean }(\mathrm{SD})\end{array}$ & $\begin{array}{c}131.4(18.6) \\
n=140\end{array}$ & $\begin{array}{c}131.7(18.6) \\
n=161\end{array}$ & $\begin{array}{c}133.7(19.5) \\
n=167\end{array}$ & $\begin{array}{c}135.2(18.8) \\
n=182\end{array}$ & $\begin{array}{c}138.6(17.9) \\
n=190\end{array}$ & $\begin{array}{c}136.9(18.7) \\
n=196\end{array}$ & 310 \\
\hline $\begin{array}{l}\text { Body mass index (BMI) } \\
\left(\mathrm{kg} / \mathrm{m}^{2}\right) \\
\text { mean (SD) }\end{array}$ & $\begin{array}{c}17.5(5.0) \\
n=137\end{array}$ & $\begin{array}{c}17.9(5.2) \\
n=161\end{array}$ & $\begin{array}{c}18.3(4.8) \\
n=162\end{array}$ & $\begin{array}{c}18.7(4.9) \\
n=181\end{array}$ & $\begin{array}{c}19.8(5.7) \\
n=186\end{array}$ & $\begin{array}{c}19.4(5.5) \\
n=194\end{array}$ & 309 \\
\hline $\begin{array}{l}\text { Total number of Illness } \\
\text { episodes, } \\
\text { mean (SD) }\end{array}$ & $\begin{array}{c}2.9(2.7) \\
n=155\end{array}$ & $\begin{array}{c}3.2(2.6) \\
n=175\end{array}$ & $\begin{array}{c}2.6(2.4) \\
n=186\end{array}$ & $\begin{array}{c}3.1(2.8) \\
n=190\end{array}$ & $\begin{array}{c}2.8(2.9) \\
n=196\end{array}$ & $\begin{array}{c}2.3(2.4) \\
n=202\end{array}$ & 316 \\
\hline $\begin{array}{l}\text { Cumulative length of } \\
\text { hospital stay (days), } \\
\text { mean (SD) }\end{array}$ & $\begin{array}{c}1.0(3.2) \\
n=155\end{array}$ & $\begin{array}{c}2.3(8.0) \\
n=186\end{array}$ & $\begin{array}{c}1.3(4.4) \\
n=193\end{array}$ & $\begin{array}{c}1.7(7.1) \\
n=204\end{array}$ & $\begin{array}{l}2(6.1) \\
n=218\end{array}$ & $\begin{array}{c}3.1(11.5) \\
n=223\end{array}$ & 322 \\
\hline $\begin{array}{l}\text { Physical Component } \\
\text { Summary Score, mean } \\
\text { (SD) }\end{array}$ & & $\begin{array}{c}49.9(9.0) \\
n=174\end{array}$ & & $\begin{array}{c}49.9(9.2) \\
n=160\end{array}$ & $\begin{array}{c}48.5(9.6) \\
n=195\end{array}$ & $\begin{array}{c}49.3(9.5) \\
n=203\end{array}$ & 296 \\
\hline $\begin{array}{l}\text { Mental Component } \\
\text { Summary Score, mean } \\
\text { (SD) }\end{array}$ & & $\begin{array}{c}40.3(10.5) \\
n=174\end{array}$ & & $\begin{array}{c}39.8(10.2) \\
n=160\end{array}$ & $\begin{array}{c}43.1(10.0) \\
n=195\end{array}$ & $\begin{array}{c}44.4(9.9) \\
n=203\end{array}$ & 296 \\
\hline
\end{tabular}

$\mathrm{n}$, number of responses; SD, standard deviation 
Table 4. Effects of age, gastrostomy placement and their interaction on nutritional status, physical health and parental well-being outcomes in Rett syndrome females with suboptimal weight (weight-for-age z-score <-1) during the follow-up period

\begin{tabular}{|c|c|c|c|c|c|c|c|c|c|c|c|c|c|c|}
\hline & \multicolumn{2}{|c|}{ Weight (kg) } & \multicolumn{2}{|c|}{ Height $(\mathrm{cm})$} & \multicolumn{2}{|c|}{ BMI $\left(\mathrm{kg} / \mathrm{m}^{2}\right)$} & \multicolumn{2}{|c|}{$\begin{array}{l}\text { Total number of } \\
\text { illness episodes }\end{array}$} & \multicolumn{2}{|c|}{$\begin{array}{l}\text { Cumulative length } \\
\text { of hospital stay (days) }\end{array}$} & \multicolumn{2}{|c|}{ PCS score } & \multicolumn{2}{|c|}{ MCS score } \\
\hline Number of individuals & \multirow{2}{*}{\multicolumn{2}{|c|}{$\begin{array}{ll}173 \\
670\end{array}$}} & \multicolumn{2}{|r|}{173} & \multicolumn{2}{|r|}{173} & \multicolumn{2}{|r|}{172} & \multicolumn{2}{|c|}{173} & \multicolumn{2}{|r|}{110} & \multicolumn{2}{|r|}{110} \\
\hline \multirow{2}{*}{ Number of observations } & & & \multicolumn{2}{|r|}{632} & \multicolumn{2}{|r|}{625} & \multicolumn{2}{|r|}{641} & \multicolumn{2}{|c|}{708} & \multicolumn{2}{|r|}{298} & \multicolumn{2}{|r|}{298} \\
\hline & $\beta^{\mathrm{a}}$ & $95 \% \mathrm{Cl}$ & $\beta^{\mathrm{a}}$ & $95 \% \mathrm{Cl}$ & $\beta^{\mathrm{a}}$ & $95 \% \mathrm{Cl}$ & $\mathrm{IRR}^{\mathrm{a}}$ & $95 \% \mathrm{Cl}$ & $\mathrm{IRR}^{\mathrm{a}}$ & $95 \% \mathrm{Cl}$ & $\beta^{\mathrm{b}}$ & $95 \% \mathrm{Cl}$ & $\beta^{c}$ & $95 \% \mathrm{Cl}$ \\
\hline GASTROSTOMY & 1.46 & $-0.21,3.13$ & -0.63 & $-3.05,1.80$ & 0.87 & $0.02,1.73$ & 1.06 & \begin{tabular}{|l|}
$0.87,1.29$ \\
\end{tabular} & 2.08 & $0.86,5.04$ & -0.45 & $-3.08,2.19$ & -1.25 & $-4.25,1.75$ \\
\hline AGE & 1.11 & $0.93,1.28$ & 1.66 & $1.44,1.88$ & 0.26 & $0.19,0.33$ & 0.95 & $0.94,0.97$ & 1.00 & $0.94,1.08$ & -0.21 & $-0.55,0.13$ & 0.12 & $-0.23,0.46$ \\
\hline GASTROSTOMY X AGE & 0.12 & $-0.08,0.32$ & 0.10 & $-0.20,0.40$ & 0.01 & $-0.10,0.12$ & 1.02 & \begin{tabular}{|l|}
$0.99,1.04$ \\
\end{tabular} & 0.94 & $0.84,1.05$ & -0.11 & $-0.45,0.23$ & -0.10 & $-0.51,0.30$ \\
\hline AGE $^{2}$ & -0.04 & $-0.06,-0.03$ & -0.13 & $-0.15,-0.12$ & 0.004 & $-0.01,0.01$ & & & & & & & & \\
\hline GASTROSTOMY X AGE² & -0.02 & $-0.04,-0.004$ & 0.04 & $0.01,0.07$ & -0.02 & $-0.03,-0.01$ & & & & & & & & \\
\hline & & & & & & & & & & & & & & \\
\hline
\end{tabular}

adjusted for mutation type, mobility, breath holding and socio-economic status

${ }^{b}$ adjusted for mutation type, mobility, sleep disturbances, breath holding, residence, respondent's age, respondent's work status, respondent's education level, household income and remoteness

' adjusted for mutation type, mobility, sleep disturbances, scoliosis, residence, respondent's age, respondent's work status, respondent's education level, household income and remoteness

$\beta$, coefficient; IRR, incidence rate ratio; $\mathrm{Cl}$, confidence interval; SES, socio-economic status; Ref, reference level; BMI, body mass index; PCS, physical component summary; MCS, mental component summary

Coefficient represents the estimated difference in mean value (e.g. weight) compared to reference level of covariate; Incidence rate ratio represents the estimated relative difference in rate of outcome (e.g. cumulative

length of hospital stay) compared to reference level of covariate 
Table 5. Descriptive statistics of the 233 Rett syndrome females with a weight-for-age z-score of less than -1 during the follow-up period

\begin{tabular}{|c|c|c|c|}
\hline & $\begin{array}{l}\text { Had never had } \\
\text { gastrostomy }\end{array}$ & $\begin{array}{c}\text { Had had } \\
\text { gastrostomy }\end{array}$ & Total \\
\hline $\mathrm{N}$ & 150 & 83 & 233 \\
\hline \multicolumn{4}{|l|}{ Mutation type, n (\%) } \\
\hline Large deletion & $9(6.0)$ & $7(8.4)$ & $16(6.9)$ \\
\hline Early truncation & $8(5.3)$ & $8(9.6)$ & $16(6.9)$ \\
\hline C-terminal deletion & $15(10.0)$ & $5(6.0)$ & $20(8.6)$ \\
\hline p.Arg106Trp & $7(4.7)$ & $3(3.6)$ & $10(4.3)$ \\
\hline p.Arg133Cys & $10(6.7)$ & $4(4.8)$ & $14(6.0)$ \\
\hline p.Thr158Met & $11(7.3)$ & $7(8.4)$ & $18(7.7)$ \\
\hline p.Arg168* & $8(5.3)$ & $11(13.3)$ & $19(8.2)$ \\
\hline p.Arg255* & $7(4.7)$ & $5(6.0)$ & $12(5.2)$ \\
\hline p.Arg270* & $8(5.3)$ & $5(6.0)$ & $13(5.6)$ \\
\hline p.Arg294* & $18(12.0)$ & $2(2.4)$ & $20(8.6)$ \\
\hline p.Arg306Cys & $9(6.0)$ & $1(1.2)$ & $10(4.3)$ \\
\hline Other & $13(8.7)$ & $7(8.4)$ & $20(8.6)$ \\
\hline Negative & $27(18.0)$ & $18(21.7)$ & $45(19.3)$ \\
\hline \multicolumn{4}{|l|}{ Learned to walk } \\
\hline Yes & $96(64.0)$ & $18(21.7)$ & $114(48.9)$ \\
\hline \multicolumn{4}{|l|}{ Mobility*, n (\%) } \\
\hline Walks normally & $41(27.3)$ & $4(4.8)$ & $45(19.3)$ \\
\hline Walking impaired & $43(28.7)$ & $7(8.4)$ & $50(21.5)$ \\
\hline Cannot walk with support & $66(44.0)$ & $72(86.8)$ & $138(59.2)$ \\
\hline \multicolumn{4}{|l|}{ Scoliosis*, n (\%) } \\
\hline None & $71(47.3)$ & $25(30.1)$ & $96(41.2)$ \\
\hline Mild & $71(47.3)$ & $40(48.2)$ & $111(47.6)$ \\
\hline Severe & $4(2.7)$ & $8(9.6)$ & $12(5.2)$ \\
\hline Surgically treated & $4(2.7)$ & $10(12.1)$ & $14(6.0)$ \\
\hline \multicolumn{4}{|l|}{ Deceased, n (\%) } \\
\hline Yes & $17(11.3)$ & $30(36.1)$ & $47(20.2)$ \\
\hline \multicolumn{4}{|l|}{ Cause of death $(n=47), n(\%)$} \\
\hline Pneumonia & $5(29.4)$ & $9(30.0)$ & $14(29.8)$ \\
\hline Aspiration/Aspiration pneumonia & $3(17.6)$ & $7(23.3)$ & $10(21.3)$ \\
\hline Respiratory failure & $2(11.8)$ & $4(13.3)$ & $6(12.8)$ \\
\hline Asphyxiation & $1(5.9)$ & $2(6.7)$ & $3(6.4)$ \\
\hline Swine influenza & $0(0)$ & $1(3.3)$ & $1(2.1)$ \\
\hline Others^ & $4(23.5)$ & $2(6.7)$ & $6(12.8)$ \\
\hline Unknown & $2(11.8)$ & $5(16.7)$ & 7 (14.9) \\
\hline
\end{tabular}

* at time of first recorded low weight z-score

^ cerebrovascular accident, epilepsy, status epilepticus, complications following surgery, "GI related" 